\title{
Invasive potential of Borrelia burgdorferi sensu stricto osp C type $L$ strains increases the possible disease risk to humans in the regions of their distribution
}

\author{
Maryna Golovchenko ${ }^{1,2}$, Radek Sima ${ }^{1}$, Ondrej Hajdusek , Libor Grubhoffer ${ }^{1,3}$, James H Oliver Jr² \\ and Nataliia Rudenko ${ }^{1,2^{*}}$
}

\begin{abstract}
Background: Analysis of Borrelia burgdorferi ospC types from the southeastern U.S.A. supported the common belief that various ospC types are geographically restricted and host specific. Being widely distributed in the region, the southeastern population of $B$. burgdorferi is represented by a surprisingly small number of ospC types. Types B, G and $\mathrm{H}$ are dominant or common and are invasive, while scarce type $\mathrm{L}$, restricted mostly to the southeastern U.S.A., is believed to rarely if ever cause human Lyme disease. OspC type $B$ and $L$ strains are represented in the region at the same rate, however their distribution among tick vectors and vertebrate hosts is unequal.

Findings: Direct diagnostics was used to analyze the ability of $B$. burgdorferi osp $C$ type $L$ strains to disseminate into host tissues. Mice were infected by subcutaneous injections of $B$. burgdorferi strains of various ospC types with different invasive capability. Spirochete levels were examined in ear, heart, bladder and joint tissues. Noninfected I. ricinus larvae were fed on infected mice until repletion. Infection rates were determined in molted nymphs. Infected nymphs were then fed on naïve mice, and spirochete transmission from infected nymphs to mice was confirmed.

Conclusions: $B$. burgdorferi ospC type $L$ strains from the southeastern U.S.A. have comparable potential to disseminate into host tissues as OspC types strains commonly associated with human Lyme disease in endemic European and North American regions. We found no difference in the invasive ability of ospC type $B$ and $L$ strains originated either from tick vectors or vertebrate hosts.
\end{abstract}

Keywords: B. burgdorferi ospC type, Invasive potential, Lyme disease, Southeastern U.S.A., Tick vector, Vertebrate host

\section{Findings}

\section{Background}

It is known that each Borrelia burgdorferi sensu lato (s.l.) species is characterized by its tick vectors, host spectrum, geographical distribution and, for the pathogenic species, its organotropism [1]. The relative invasiveness of various $B$. burgdorferi strains, classified by ospC type, reveals the ratio between that type's frequency in vector ticks compared to human patients [2].

\footnotetext{
* Correspondence: natasha@paru.cas.cz

'Biology Centre AS CR, Institute of Parasitology, Ceske Budejovice 37005, Czech Republic

${ }^{2}$ Georgia Southern University, James H. Oliver, Jr. Institute of Coastal Plain Sciences, Statesboro, GA 30460-8056, USA

Full list of author information is available at the end of the article
}

Published data on prevalence of Lyme disease (LD) spirochetes in vector ticks and vertebrate hosts in the southeastern U.S.A. qualifies this region as B. burgdorferi s.l. endemic area, despite prevailing dogma concerning LD in the United States [3]. Briefly, current dogma states that Ixodes scapularis (formerly, I. dammini) is the only vector of the spirochetes in the eastern U.S.; B. burgdorferi is antigenically and genetically uniform in North America in contrast to the situation in Europe; B. burgdorferi does not occur in wildlife in the southern U.S.A. and thus, humans in the Southeast could not acquire LD [3,4]. It is now known that the often referenced I. scapularis-Peromyscus leucopus enzootic cycle in the northeastern U.S.A. is mirrored by the I. scapularis-P. gossypinus transmission cycle 
in the Southeast which is further enhanced by Ixodes affinis and Ixodes minor as vital maintenance vectors of Borrelia in areas where they occur, and Sigmodon hispidus and Neotoma floridana as additional major reservoir hosts $[3,5]$. As the tick vectors and reservoir hosts differ significantly between the northeastern and southeastern regions, it is highly possible that $B$. burgdorferi strains that cause LD in both areas will differ as well. Our previous research showed that of the 4 osp C types, B, G, H and $\mathrm{N}$ that have been detected in LD patients in the northeastern and midwestern U.S.A., 3 types, B, G, and H, at a lower rate, are widely distributed in the southeastern United States [5]. While $O s p C$ type B is associated with severe LD around the world [6,7], ospC types $\mathrm{H}$ and $\mathrm{G}$ are commonly detected in tissues at disseminated sites of LD patients from the northeastern and midwestern U.S.A. [2,8]. B. burgdorferi ospC type $\mathrm{L}$ strains were not considered to have any impact in LD in North America in general and, in the southeastern U.S.A. particularly, because: i) ospC type L was considered to be restricted to Europe only; ii) ospC type $\mathrm{L}$ is recognized as very rare worldwide; and iii) $\operatorname{os} p C$ type $\mathrm{L}$ strains were previously detected in ticks only [2,6-9].

Globally rare $B$. burgdorferi osp $C$ type L strains are associated with the non-human biting tick $I$. affinis that feeds on the same vertebrate hosts as human-biting I. scapularis in the southeastern U.S.A. [9]. However, due to the common reservoir hosts in the feeding cycle, Borrelia strains from I. affinis might be transmitted to humans [3]. B. burgdorferi osp $C$ types $B$ and $L$ strains are the most prevalent in the region. They are represented at the same rate overall, but their distribution among the tick vectors and the rodent hosts is unequal. While $75 \%$ of highly invasive ospC type B strains were isolated from rodents and 25\% from ticks, in the case of ospC type L, host- and vector originated strains represented $37.5 \%$ and $62.5 \%$, respectively. For a long time it was believed that ospC type $\mathrm{L}$ strains are incapable of causing human LD [2]. Nevertheless, a B. burgdorferi ospC type L strain (SLV-1) was cultured from a skin biopsy from a Slovenian patient with acrodermatitis chronica atrophicans (ACA), commonly associated with $B$. afzelii infection [10]. Additional strains were isolated from I. ricinus nymphs collected in Switzerland (NE5222 and NE5266) and Slovakia (SKT-2) [5], European LD endemic regions. Another ospC type L strain (SCW-9) was isolated from secondary sites of infection of cotton rat (Sigmodon hispidus) trapped in South Carolina, U.S.A. [5,9]. The question about Lyme disease in the southeastern U.S.A. is still controversial and confounded by multiple facts and fallacies. Because ospC type $\mathrm{L}$ strains are one of the two most prevalent in this region [9], the goal of this study was to analyze the capability of $B$. burgdorferi ospC type $\mathrm{L}$ strains to disseminate into vertebrate hosts and to compare their invasive potential with infective strains.

\section{Methods}

Low passage Borrelia strains were grown in BSK-H medium (Sigma-Aldrich, U.S.A.) according to the protocol described previously $[11,12]$. Strains used for infection of laboratory mice were characterized in our previous study [5] and were selected on the basis of their ospC types defined earlier [5]: human originated $\operatorname{sspC}$ type B strain SLV-2 (collection site $46^{\circ} 3^{\prime} 17^{\prime \prime} \mathrm{N}, 14^{\circ} 30^{\prime} 21^{\prime \prime} \mathrm{E}$ ), cotton mouse (Peromyscus gossypinus) originated ospC type L strain $\mathrm{SCCH}-30\left(32^{\circ} 47^{\prime} 00^{\prime \prime} \mathrm{N}, 7^{\circ} 56^{\prime} 00^{\prime \prime} \mathrm{W}\right)$, I. ricinus nymphs originated ospC type L strain NE5222, ospC type B strain NE5264 and ospC type V strain NE5248 (46 59' $34.72^{\prime \prime} \mathrm{N}$, $6^{\circ} 55^{\prime} 54.96^{\prime \prime} \mathrm{E}$ ) and I. affinis female originated osp $C$ type

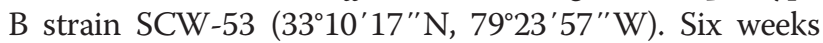
old female $\mathrm{C} 3 \mathrm{H} / \mathrm{HeN}$ mice (Jackson Laboratory, Sulzfeld, Germany) were infected by subcutaneous injections of $10^{5}$ spirochetes in $100 \mu \mathrm{l}$ of BSK-H medium per mouse (2 mice per strain). Presence of spirochetes in ear biopsies was determined at weekly intervals by PCR. Total DNA was extracted using a NucleoSpin Tissue Kit (Macherey-Nagel, Germany) according to the manufacturer's protocol. Detection of spirochetes was performed by amplification of a 154 bp fragment of flagellin gene using primers FlaF1 (AAGCAAATTTAGGTGCTTTCCAA) and FlaR1 (GCA ATCATTGCCATTGCAGA) [12]. At the $3^{\text {rd }}$ week after infection the presence of spirochetes was confirmed in all ear biopsy samples regardless of the $\operatorname{sp} C$ type of strain used for infection. I. ricinus larvae were obtained from the pathogen-free tick colony of the Institute of Parasitology (Czech Republic). At the $4^{\text {th }}$ week after inoculation, noninfected larvae were fed on infected mice until repletion (100 larvae per mouse) and left to molt. Infection rates were determined in pools of ten molted nymphs using PCR described above. Nymphs were considered to be infected if $>80 \%$ of them were PCR positive. Ten infected nymphs were then fed on naïve mice ( 5 mice per strain); spirochete transmission from infected nymph to mice was determined as described above. At week $6^{\text {th }}$, spirochete load was determined in positive biopsies from mouse ear, heart, bladder and joint by quantitative PCR using primers described above, the TaqMan FlaProbe1 (TGCTACAA CCTCATCTGTCATTGTAGCATCTTTTATTTG) and a LightCycler 480 (Roche) [13]. Spirochete burden in tissues was normalized to mouse actin using previously described methods [14]. Amplification and sequencing of spirochete osp $C$ genes from final mouse samples confirmed their identity to the $o s p C$ genes of $B$. burgdorferi strains used for initial infection [5]. All laboratory animals were treated in accordance with the Animal Protection Law of the Czech Republic No. 246/1992 Sb., ethics approval No. 137/2008.

\section{Results and conclusions}

PCR was used to confirm infection of laboratory mice with invasive $B$. burgdorferi ospC type B strains and $\operatorname{sp} p C$ 
Table 1 Invasive potential of B. burgdorferi sensu stricto strains with different ospC types

\begin{tabular}{|c|c|c|c|c|c|c|c|c|c|c|c|c|c|c|c|c|}
\hline \multicolumn{2}{|c|}{ Mice } & \multicolumn{5}{|l|}{ Borrelia } & \multicolumn{6}{|c|}{ Ear punch biopsy (week) } & \multicolumn{4}{|c|}{ qPCR results (\#) } \\
\hline Qty & Strain & Origin & Species & Strain & Source & $\operatorname{ospC}$ & 1 & 2 & 3 & 4 & 5 & $6^{*}$ & Ear & Bladder & Joint & Heart \\
\hline 2 & $\mathrm{C} 3 \mathrm{H} / \mathrm{HeN}$ & Europe & Bb s.s. & SLV-2 & human & type B & - & - & + & + & + & $2 / 2$ & $12.0 \pm 3.0$ & $9.5 \pm 2.5$ & $15.0 \pm 9.0$ & $3.0 \pm 1.0$ \\
\hline 5 & $\mathrm{C} 3 \mathrm{H} / \mathrm{HeN}$ & U.S.A. & Bb s.s. & $\mathrm{SCCH}-30$ & P.gossypinus & type L & - & - & + & + & + & $4 / 5$ & $7.0 \pm 2.4$ & $7.0 \pm 1.2$ & $33.0 \pm 18.5$ & $5.0 \pm 1$. \\
\hline & $\mathrm{C} 3 \mathrm{H} / \mathrm{HeN}$ & Europe & Bb s.s. & NE5264 & I. ricinus (n) & type B & - & - & + & + & + & $2 / 2$ & $18.5 \pm 5.3$ & $18.7 \pm 9.5$ & $14.6 \pm 1.8$ & $2.9 \pm 0$ \\
\hline 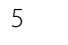 & $\mathrm{C} 3 \mathrm{H} / \mathrm{HeN}$ & Europe & Bb s.s. & NE5222 & I. ricinus (n) & type $L$ & - & - & + & + & + & $3 / 5$ & $14.6 \pm 2.7$ & $20.7 \pm 6.2$ & $14.0 \pm 3.4$ & $2.5 \pm 0$ \\
\hline 2 & $\mathrm{C} 3 \mathrm{H} / \mathrm{HeN}$ & U.S.A. & Bb s.s. & SCW-53 & 1. affinis (f) & type B & - & - & + & + & + & $2 / 2$ & $6.5 \pm 0.5$ & $12.0 \pm 1.0$ & $174.5 \pm 70.5$ & $3.0 \pm 2$ \\
\hline 2 & $\mathrm{C} 3 \mathrm{H} / \mathrm{HeN}$ & Europe & Bb s.s. & NE5248 & I. ricinus (n) & type V & - & + & + & + & + & $1 / 2$ & 8 & 20 & 6 & 4 \\
\hline
\end{tabular}

Qty- quantity: \# of mice/experiment; $(n)$ - nymph; ( $f$ - female; $6 *$ - total number of infected mice at 6 weeks time point; qPCR results are expressed as means \pm SEM, (\#) - number of spirochetes $/ 10^{5}$ murine genomes.

type L strains, previously found only in ticks (Table 1). An $o s p C$ type $\mathrm{V}$ strain was included in the analysis for comparison, as it was found in ticks and in sites of local infection in humans. The same pattern of transmission of $\operatorname{ssp} C$ type $\mathrm{B}$ and type $\mathrm{L}$ strains of the LD spirochete from infected host to tick vector and then from infected tick vector to uninfected host was revealed using the designed protocol. It is interesting to note that the results of dissemination of host originated $\operatorname{sp} \mathrm{C}$ type B (human, SLV-2) and L (rodent, SCCH-30) strains were comparable in each tissue analyzed (Table 1). Dissemination ability of ospC type B (NE5264) and L (NE5222) strains originated from human biting I. ricinus was almost equal in each tissue (Table 1). However, the load of spirochetes of ospC type B (SCW-53) originated from non-human biting $I$. affinis was more than 10 times higher in mouse joints than was the spirochete load of human-originated ospC type B (SLV-2) or human-biting I. ricinus originated (NE5264) strains. Our results confirm that tick originated strains NE5264 and NE5222 of ospC types B and $\mathrm{L}$ and host originated $\operatorname{ospC}$ type B strain SLV-2, show the same pattern of dissemination in all analyzed host tissues, with no preferential site of infection. Identical pattern of dissemination was revealed for non-human biting tick originated $\operatorname{ssp} C$ type B strain SCW-53, and rodent originated $o s p C$ type L strain $\mathrm{SCCH}-30$ (strains from South Carolina, U.S.A.), with joints as the preferable site of spirochete accumulation. Analysis of I. ricinus originated ospC type V strain NE5248 showed that, in contrast to types $\mathrm{B}$ and $\mathrm{L}$, this $o s p C$ type preferably disseminates into bladder, not joints (Table 1).

B. burgdorferi ospC type L strains originated from human, rodent or hard tick were able to disseminate into laboratory mice as well as invasive $o s p C$ type B strains that are responsible for systemic disease in humans. Therefore, further study on the pathogenicity of B. burgdorferi ospC type L strains is warranted. The qPCR results in this study defined heart as a tissue with the lowest load of spirochetes, while the joints showed the highest load of borrelia in mice infected either with ospC type B or L strains (Table 1). Our results support the association of
B. burgdorferi with Lyme arthritis $[15,16]$. The confirmed ability of $o s p C$ type L strains to disseminate into vertebrate host tissues in the same manner as invasive ospC type B strains, known to be responsible for severe disease in humans worldwide, increases the possible disease risk to humans in the southeastern U.S.A., the region, where studied strains are widely distributed [5].

\section{Competing interests}

The authors declare that they have no competing interests.

\section{Authors' contributions}

MG and NR designed the experimental scheme, maintained strain cultivation and analysis, sequence analysis, results evaluation and drafted the manuscript. $\mathrm{RS}$ and $\mathrm{OH}$ carried out the transmission experiments with laboratory animals and ticks, PCR and quantitative PCR, results evaluation and manuscript editing. LG secured financial support of the project, evaluated results and edited the manuscript. JHO isolated host- and vector-associated strains, maintained collection of B. burgdorferi isolates, and secured financial support of the project, evaluated results and edited the manuscript. All authors read and approved the final version of the manuscript.

\section{Acknowledgements}

We are grateful to Prof. E. Ruzić-Sabljić and Prof. L. Gern for generously sharing with us strains SLV-2 [ERS] and NE5222, NE5248 and NE5264 [LG]. We thank Kerry Clark for critical reading and editing of the manuscript and for helpful comments. This research was supported by European FP7 project 278976 ANTIGONE, GSU Foundation (USA), grants 13-27630P \& 13-12816P from the Grant agency of the Czech Republic and with institutional support RVO: 60077344 from Biology Centre, Institute of Parasitology (Czech Republic). $\mathrm{OH}$ was further supported by the EU FP7 project MODBIOLIN No. 316304.

\section{Author details}

${ }^{1}$ Biology Centre AS CR, Institute of Parasitology, Ceske Budejovice 37005, Czech Republic. ${ }^{2}$ Georgia Southern University, James H. Oliver, Jr. Institute of Coastal Plain Sciences, Statesboro, GA 30460-8056, USA. ${ }^{3}$ University of South Bohemia, Ceske Budejovice 37005, Czech Republic.

Received: 18 September 2014 Accepted: 12 November 2014 Published online: 28 November 2014

\section{References}

1. Baranton G, Marti Ras N, Postic D: Molecular epidemiology of the aetiological agents of Lyme borreliosis. Wien Klin Wochenschr 1998, 110:850-855.

2. Dykhuizen DE, Brisson D, Sandigursky S, Wormser GP, Nowakowski J Nadelman RB, Schwartz I: The propensity of different Borrelia burgdorferi sensu stricto genotypes to cause disseminated infections in humans. Am J Trop Med Hyg 2008, 78:806-810.

3. Oliver JH Jr: Lyme borreliosis in the southern United States: a review. J Parasitol 1996, 82:926-935. 
4. Lane RS, Piesman J, Burgdorfer W: Lyme borreliosis: relation of its causative agent to its vectors and hosts in North America and Europe. Annu Rev Entomol 1991, 36:587-609.

5. Rudenko N, Golovchenko M, Hönig V, Mallátová N, Krbková L, Mikulásek P, Fedorova N, Belfiore NM, Grubhoffer L, Lane RS, Oliver JH Jr: Detection of Borrelia burgdorferi sensu stricto ospC alleles associated with human Lyme borreliosis worldwide in non-human-biting tick Ixodes affinis and rodent hosts in southeastern United States. Appl Environ Microbiol 2013, 79:1444-1453.

6. Seinost G, Dykhuizen DE, Dattwyler RJ, Golde WT, Dunn JJ, Wang IN, Wormser GP, Schriefer ME, Luft BJ: Four clones of Borrelia burgdorferi sensu stricto cause invasive infection in humans. Infect Immun 1999, 67:3518-3524.

7. Qiu WG, Bruno JF, McCaig WD, Xu Y, Livey I, Schriefer ME, Luft BJ: Wide distribution of a high-virulence Borrelia burgdorferi clone in Europe and North America. Emerg Infect Dis 2008, 14:1097-1104.

8. Brisson D, Baxamusa N, Schwartz I, Wormser GP: Biodiversity of Borrelia burgdorferi strains in tissues of Lyme disease patients. PLoS One 2011, 6:e22926.

9. Rudenko N, Golovchenko M, Grubhoffer L, Oliver JH Jr: The rare $\operatorname{csp} \mathrm{C}$ allele L of Borrelia burgdorferi sensu stricto, commonly found among samples collected in a coastal plain area of the southeastern United States, is associated with Ixodes affinis ticks and local rodent hosts Peromyscus gossypinus and Sigmodon hispidus. Appl Environ Microbiol 2013, 79:1403-1406.

10. Ruzić-Sabljić E, Zore A, Strle F: Characterization of Borrelia burgdorferi sensu lato isolates by pulsed-field gel electrophoresis after Mlul restriction of genomic DNA. Res Microbiol 2008, 159:441-448.

11. Rudenko N, Golovchenko M, Grubhoffer L, Oliver HJ Jr: Borrelia carolinensis sp. nov., a new (14th) member of the Borrelia burgdorferi sensu lato complex from the southeastern region of the United States. J Clin Microbiol 2009, 47:134-141.

12. Rudenko N, Golovchenko M, Lin T, Gao L, Grubhoffer L, Oliver HJ Jr: Delineation of a new species of the Borrelia burgdorferi sensu lato complex, Borrelia americana sp. nov. J Clin Microbiol 2009, 47:3875-3880.

13. Schwaiger M, Péter O, Cassinotti P: Routine diagnosis of Borrelia burgdorferi (sensu lato) infections using a real-time PCR assay. Clin Microbiol Infect 2001, 7:461-469.

14. Dai J, Wang P, Adusumilli S, Booth CJ, Narasimhan S, Anguita J, Fikrig E: Antibodies against a tick protein, Salp15, protect mice from the Lyme disease agent. Cell Host Microbe 2009, 6:482-492.

15. Steere A: Lyme disease. N Engl J Med 1998, 321:586-596.

16. Oschmann P, Dorndorf W, Hornig C, Schäfer C, Wellensiek HJ, Pflughaupt KW: Stages and syndromes of neuroborreliosis. J Neurol 1998, 245:262-272.

doi:10.1186/s13071-014-0538-y

Cite this article as: Golovchenko et al.: Invasive potential of Borrelia burgdorferi sensu stricto osp $C$ type $L$ strains increases the possible disease risk to humans in the regions of their distribution. Parasites \& Vectors 2014 7:538

\section{Submit your next manuscript to BioMed Central and take full advantage of:}

- Convenient online submission

- Thorough peer review

- No space constraints or color figure charges

- Immediate publication on acceptance

- Inclusion in PubMed, CAS, Scopus and Google Scholar

- Research which is freely available for redistribution 